\title{
Comentarios
}

\section{Las reformas penales y los derechos humanos}

Durante todo el mes de octubre, los medios de difusión masivos continuaron informando sobre innumerables hechos de violencia. Solamente del seguimiento de la nota periodística registramos, a lo largo del período, 79 personas fallecidas. La cifra se inserta dentro del promedio establecido a partir del recuento realizado en los dos meses precedentes, siempre utilizando la misma fuente: 60 , en septicmbre, y 69, en agosto. En total, 208 muertes en tres meses.

Frente a estos datos, sin duda, la inmensa mayoría de los salvadoreños se preocupa. La finalización de la guerra generó expectativas en torno a la conclusión de la violencia y sus consecuencias mortales. Sin embargo, el eufórico ambiente inicial que siguió a los primeros días de enero, producto de la firma de la paz, poco a poco se ha ido ensombreciendo con las dificultades en cuanto al cumplimiento de los acuerdos por las partes y por el considerable grado de inseguridad en que vivimos. Entonces, cabe preguntarse: ¿qué está sucediendo ahora en El Salvador? Al aventurar una reflexión inicial más que una respuesta, se debe partir de que en El Salvador el conflicto bélico ha concluido, pero no ha sucedido lo mismo con el conflicto social. Desde este último se debe explicar por qué la violencia sigue presente y de modo preponderante en nuestro país.

El análisis simplista o interesado, fácilmente atribuye todos estos hechos al "aumento de la ola delincuencial". Pero eso, realmente, puede resultar peligroso al impedir llegar a las causas reales del fenómeno. Un primer paso para un análisis más serio obliga a observar cómo se produjeron las numerosas víctimas antes mencionadas.

En agosto, dijimos, los hechos de violencia dejaron 69 personas muertas, en las circunstancias siguientes, 33 a manos de "individuos desconocidos", 22 por la "delincuencia común" y 14 cadáveres con evidentes señales de tortura, en el clásico estilo de los "escuadrones de la muerte". Destaca el caso de José Alejandro Jaco, sindicalista de la Asociación de Trabajadores del Ministerio de Obras Públicas (ATMOP), asesinado el 3 de agosto en presencia de sus familiares por "individuos desconocidos", quienes se introdujeron en su casa de habitación, ubicada en la occidental ciudad de Santa Ana.

En septiembre fueron 60 los muertos registrados y las circunstancias fueron las siguientes: 27 víctimas de la "delincuencia común", 18 asesinados por "individuos desconocidos", 11 personas cuyos cuerpos presentaban señales de tortura, 3 por la explosión de una granada y un individuo, supuesto "malhechor", que falleció en un "enfrentamiento" con agentes de la Policía Nacional. Finalmente, en octubre, la cantidad ascendió a 79, de los cuales 36 se le atribuyen a la "delincuencia común" y 24 a "individuos desconocidos". Además, 7 murieron como resultado de la explosión de granadas, 6 aparecieron con señales de tortura, 2 fueron acribillados por presuntos "terroristas", un 
agente de policía y un civil detenido fallecieron cuando éste último intentó huir, una persona fue asesinada por un efectivo de la Quinta Brigada de Infantería y otra por un agente de la policía.

Los derechos humanos se ven afectados por el proceso de transición. La reducción de la Fuerza Armada, los cambios experimentados en su doctrina y el desmantelamiento de los cuerpos de seguridad, "responsables en gran medida de innumerables abusos, atropellos y violaciones a los derechos humanos" (Proceso, 1992, 510), han generado un gran desempleo dentro de las filas de un poder acostumbrado a obtener beneficios económicos ilícitos, pero de manera encubierta. No cabe duda de que en El Salvador, la desocupación de esta "mano de obra" es abundante.

Un buen porcentaje de los hechos de violencia registrados en este periodo pueden ser explicados lógicamente. La delincuencia común es un fenómeno innegable y preocupante, pero no es algo nuevo. Sin embargo, es más inquietante que la inseguridad generalizada se pretenda explicar exclusivamente en términos de delincuencia común. A causa de las transformaciones de los acuerdos de paz, los poderes militar y policial se sienten traicionados y consideran que su existencia está en peligro. En consecuencia, dejan actuar a la delincuencia común. Es tan frustrante su situación que no debe descartarse la participación activa de los militares y policías en esta ola de delitos. Sus objetivos son, por un lado, asegurarse ingresos sustanciales y, por el otro, atemorizar a la opinión pública y favorecer sus intereses corporativos.

La situación se torna más oscura cuando, lastimosamente, las instancias encargadas de diseñar y aplicar una política criminal adecuada entran en serias contradicciones. Este es el caso de la polémica que, también en el transcurso del mes de octubre y los primeros días de noviembre, la prensa escrita del país ha registrado. El centro de la polémica radica en las reformas de los procedimientos penales en relación con los derechos del imputado, impulsadas por el Ministerio de Justicia. Las posturas se encuentran claramente definidas. Por un lado, están las que sostienen que dichas reformas promueven la delincuencia; por el otro, quienes afirman que con éstas se pretende defender a la población en general. Tan encontradas ópticas exigen un análisis más profundo que contribuya a una verdadera educación ciudadana y supere las manipulaciones tendenciosas sobre el tema. Para ello, lo primero es conocer los cambios introducidos en la ley que han motivado el debate, de modo especial la asesoría legal y la defenesoría pública.

En mayo, el Organo Legislativo emitió el Decreto № 238, mediante el cual se introdujeron importantes reformas en el Código Procesal Penal y en la Ley Orgánica del Ministerio Público. Con las modificaciones al artículo 46 de dicho Código, todo imputado - sin mediar como antes "razones de seguridad o de orden público"- "será considerado inocente mientras no se declare su culpabilidad en sentencia ejecutoriada, de conformidad a la Ley y mediante juicio público". Desde 1789 , la Declaración de los Derechos del Hombre y del Ciudadano, en su artículo noveno, hablaba de la presunción de inocencia, considerada en la actualidad como la garantía judicial fundamental en materia penal. Así, ésta se encuentra contemplada en el doceavo artículo de nuestra Constitución y en los principales instrumentos de los sistemas universal e interamericano de los derechos humanos: la Declaración Universal, la Declaración Americana, la Convención Americana y el Pacto Internacional de Derechos Civiles y Políticos.

La reforma introducida con el Decreto № 238 contempla, además, asegurar las garantías necesarias para la defensa del imputado. Ello, mediante la notificación "inmediata y comprensible, por parte del tribunal, o del órgano auxiliar o autoridad que realice la captura", de los derechos que le corresponden. Estos derechos son: conocer por qué se le captura y quién ordenó dicha acción, al mostrar la correspondiente orden de detención dictada por autoridad competente; poder comunicar rápidamente el hecho a la persona, asociación o entidad que considere conveniente el imputado; no ser sometido a presiones de cualquier tipo, contrarias a su dignidad y que lo intimiden, lo induzcan o alteren su libre voluntad; contar, en caso necesario, con la asistencia de un traductor o intérprete; que no se le impida su libertad de movimiento "en el lugar y durante la realización de un acto proce- 
sal o diligencia extrajudicial, sin perjuicio de las medidas precautorias que en casos especiales y a su prudente arbitrio estime ordenar el juez". Aquí no hay nada exótico o contrario a la democracia que motive a rasgarse las vestiduras.

Pero los derechos del imputado que más han despertado inquietudes, algunas de las cuales sólo merecen el calificativo de retardatarias, son los relacionados con su defensa. El numeral tercero del artículo 46, del Código Procesal Penal, establece que el imputado debe "ser asistido en forma inmediata desde el inicio de las diligencias extrajudiciales o del proceso por el defensor que designe él o sus parientes, y en defecto de éste por un defensor público o por un defensor de oficio". El siguiente numeral, el cuarto, señala que el imputado tiene derecho a "abstenerse de declarar; y si acepta hacerlo, a que su defensor esté presente al momento de rendir su declaración y en aquellas otras diligencias en que se requiera la presencia del imputado".

En el sistema de protección de Naciones Unidas, el mecanismo principal encargado de examinar las denuncias individuales es el Comité de Derechos Humanos, cuyo origen se encuentra en el Pacto Internacional de Derechos Civiles y Políti$\cos$. De un comentario de este órgano independiente al artículo 14, 3, del mencionado Pacto, rescatamos lo siguiente: "los medios adecuados para la preparación de su defensas... deben incluir... la oportunidad de contratar un abogado y de comunicarse con éste. Cuando el acusado no desee defenderse personalmente ni solicite una persona o una asociación de su elección, debe recurrir a un abogado". Pero la Comisión Interamericana de Derechos Humanos va más allá, al precisar la obligatoria asistencia desde que el imputado es sometido al primer interrogatorio.

Los argumentos de los que se oponen a los cambios pueden ilustrarse con las declaraciones del Fiscal General de la República, el doctor Roberto Mendoza Jerez, quien - según una nota aparecida en un periódico nacional- expresó a los diputados miembros de una comisión de la asamblea legislativa que "queremos tener leyes de Suiza, pero la realidad es que tenemos las de la selva". Desde esta perspectiva, una gran cantidad "de delincuentes que guardan prisión podrían ampararse a la recién aprobada Ley de Defensoría Pública para salir libres, lo cual causaría un caos jurídico". En el mismo tono, un pronunciamiento de la Asociación de Abogados de El Salvador decía: "Las reformas penales que suprimen las presunciones de culpabilidad y nulifican los procedimientos policiales por la inasistencia de abogados a los detenidos, sólo pondrán en la calle a los secuestradores, asaltantes, violadores y asesinos".

Sin embargo, hay quienes opinan diferente. Dice el doctor Jorge Alberto Gómez Arias, decano de la Facultad de Derecho de la Universidad de El Salvador, "la exigencia de que el imputado cuente con la asistencia de un defensor desde las primeras diligencias policiales aparece textualmente... en el artículo 12, inciso segundo de la Constitución vigente desde 1983". Para el funcionario de la universidad, considerar las normas para la asistencia legal y defensoría pública -que se limitan "a desarrollar aquella norma constitucional"- como una legislación propia de Suiza, nos obligaría a decir que nuestra Carta Magna no es salvadoreña, sino de dicho país europeo.

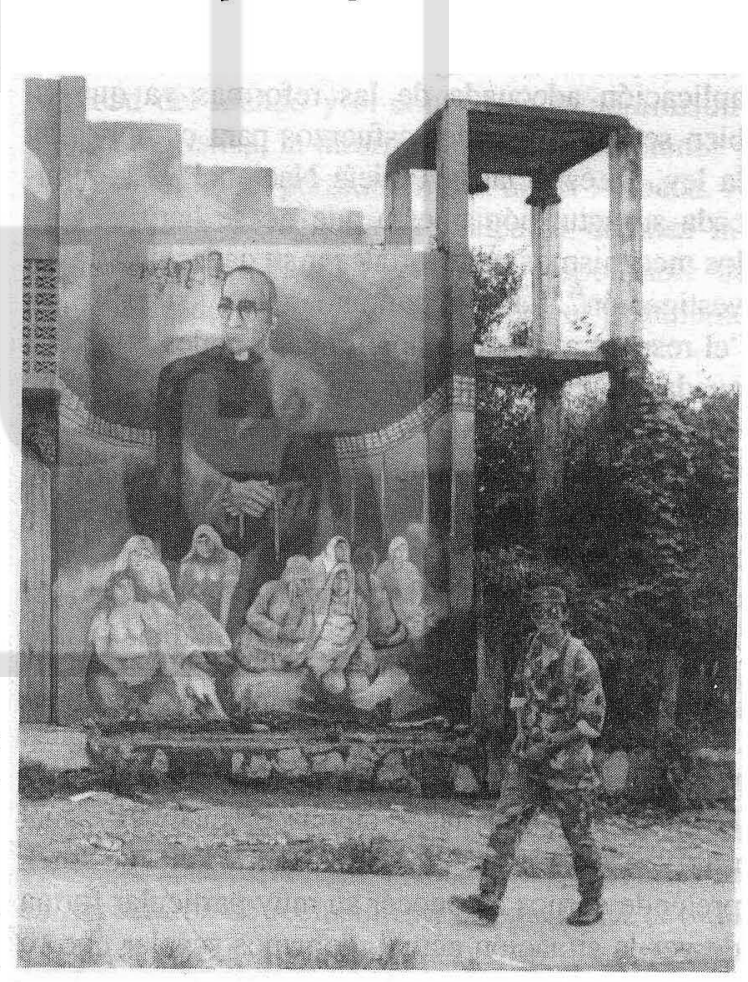


El licenciado Francisco Díaz, director ejecutivo del Centro de Estudios para la Aplicación del Derecho, se refiere también a las diferencias que se quieren establecer entre nuestra realidad y la situación en que se encuentran otros pueblos. Para él, algo hay de cierto "en nuestra falta de civilización y cultura, y muy buena muestra de ello son, precisamente, las normas penales y procesales penales que nos rigen hasta el presente. Esas normas, expresión de la voluntad soberana del Estado, están más cerca de las concepciones y de los procedimientos incivilizados e incultos de la inquisición que de cualquiera de los procedimientos modernos, y violan con toda evidencia las normas constitucionales del debido proceso".

El 1 de octubre, los participantes en una actividad organizada por el Instituto Salvadoreño de Derecho Penal y Procesal Penal coincidieron, tal como apunta el boletín Actualidad Jurídica, № 6, del Centro de Investigación y Capacitación, Proyecto de Reforma Judicial, "en destacar la importancia de las reformas y la necesidad de fortalecer su aplicación mediante una acción coordinada de todas las instituciones vinculadas al quehacer judicial". Según el mencionado boletín, en el evento surgieron "dudas acerca de si se está logrando una aplicación adecuada de las reformas ya que, si bien se hacen grandes esfuerzos para cumplir con la ley, en especial la Policía Nacional ve complicada su actuación puesto que no se han previsto los mecanismos para fortalecer su capacidad de investigación". La nota puntualiza que, sin embargo, "el respeto a los derechos fundamentales no puede quedar supeditado a razones de eficacia, ya que estas nuevas normas no hacen si no tomar operativos los derechos contenidos, desde hace varios años, en la Constitución, que no habían sido hasta ahora llevados a la práctica". Finalmente, se destacó la importancia de la presencia del defensor del imputado, "tanto en un ámbito extrajudicial como en la sede judicial".

Ante este tipo de opiniones, algunas de ellas tan temerarias como las del Fiscal General de la República, cabría hacer ciertas precisiones. $\mathrm{Si}$ al referirse a las leyes de "la selva", Mendoza Jerez pretende darnos a conocer su muy particular forma de ver la situación actual, debemos señalar que se quedó corto. En nuestro país ha imperado la llamada "ley de la selva", en tanto la impunidad se ha paseado a lo largo y ancho del territorio nacional, mientras cientos de miles de salvadoreños han sufrido por la represión selectiva e indiscriminada del Estado y por las violaciones flagrantes a las normas del derecho internacional humanitario. En la actualidad, la impunidad - la ausencia de castigo - continúa amparada en las gravísimas deficiencias del sistema judicial y en el inadecuado desempeño de muchos funcionarios encargados de administrar justicia en nuestro país. Y no sólo lo decimos nosotros. También el profesor José Antonio Pastor Ridruejo, Representante Especial del Secretario General de Naciones Unidas, señaló en uno de sus informes a la Comisión de Derechos Humanos del organismo intemacional que "la actividad de la justicia penal dirigida a la investigación y castigo de las graves violaciones a los derechos humanos continúa siendo sumamente insatisfactoria lo que, unido a la promulgación y aplicación de la ley de amnistía de octubre de 1987, propicia y refuerza un nocivo clima de impunidad".

En ese marco, es preocupante que hasta la fecha ni siquiera el caso del licenciado José Eduardo Pineda Valenzuela, alto funcionario de la Procuraduría para la Defensa de los Derechos Humanos, haya sido esclarecido. ¿Qué pueden esperar los familiares de las víctimas de tantos hechos sangrientos como los registrados por el IDHUCA durante agosto, septiembre y octubre? ¿Se podrán aclarar mediante investigaciones científicas y se podrá hacer justicia?

Por si esto fuera poco, la Comisión Interamericana de Derechos Humanos dio "por ciertos los hechos relacionados con la masacre de Las Hojas", declaró que "el gobierno de El Salvador es responsable por los hechos denunciados en la comunicación del 27 de enero de 1989, por las ejecuciones sumarias y extrajudiciales de aproximadamente 74 víctimas civiles" y que "no ha cumplido con las obligaciones de garantizar el libre y pleno ejercicio de los derechos humanos y garantías fundamentales de todas las personas sujetas a su jurisdicción, impuestas por el artículo $1^{\circ}$ de la Convención Americana sobre Derechos Humanos". Además, recomendó a las autoridades guber- 
namentales "una exhaustiva, rápida, completa e imparcial investigación sobre los hechos denunciados, a fin de identificar a todas las víctimas y a los responsables", los cuales deben recibir "las sanciones que tan grave proceder exige", así como la adopción de "las medidas necesarias para impedir la comisión de hechos similares en lo sucesivo", la reparación de "las consecuencias de la situación que ha configurado la vulneración de los derechos antes enunciados" y el pago de "una justa indemnización compensatoria a los familiares de las víctimas de la masacre". Hasta la fecha, las instancias gubernamentales correspondientes no han cumplido con tales recomendaciones. Nos preguntamos si estas actitudes favorecen o no a los transgresores de la ley.

Más todavía, ¿qué señales se pretenden enviar a los violadores de los derechos humanos cuando, de manera irresponsable, se están poniendo grandes obstáculos al esclarecimiento de la verdad en el caso de El Mozote? Algunos singulares personajes empiezan a insinuar, o afirman abiertamente, que los cientos de víctimas en El Mozote fallecieron como resultado de un "enfrentamiento armado". El doctor Juan Mateu LLort, director del Instituto de Medicina Legal, arremete contra la licenciada María Julia Hernández de la Oficina de Tutela Legal del Arzobispado, pretendiendo descalificar su actuación, aventurándose a declarar —en forma peligrosa y contraria a su supuesto papel de investigador técnico imparcial- que los niños masacrados "eran guerrilleros". El funcionario forense basa su ligereza en un comentario hecho por el ex capitán de la Fuerza Armada, Francisco Mena Sandoval, quien al describir su experiencia menciona una escuela de entrenamiento militar en El Mozote. Un poco más de acuciosidad, tan necesaria para el buen desempeño de su labor, le habría ayudado al doctor Mateu LLort a descubrir que la referencia hecha por Mena Sandoval está fechada varios años después de ocurrida la masacre.

De igual manera, inquieta la actitud del presidente Alfredo Cristiani quien, como comandante general de la institución castrense, niega poseer información pertinente para el esclarecimiento de esos hechos. Para ello, aduce que en esa época

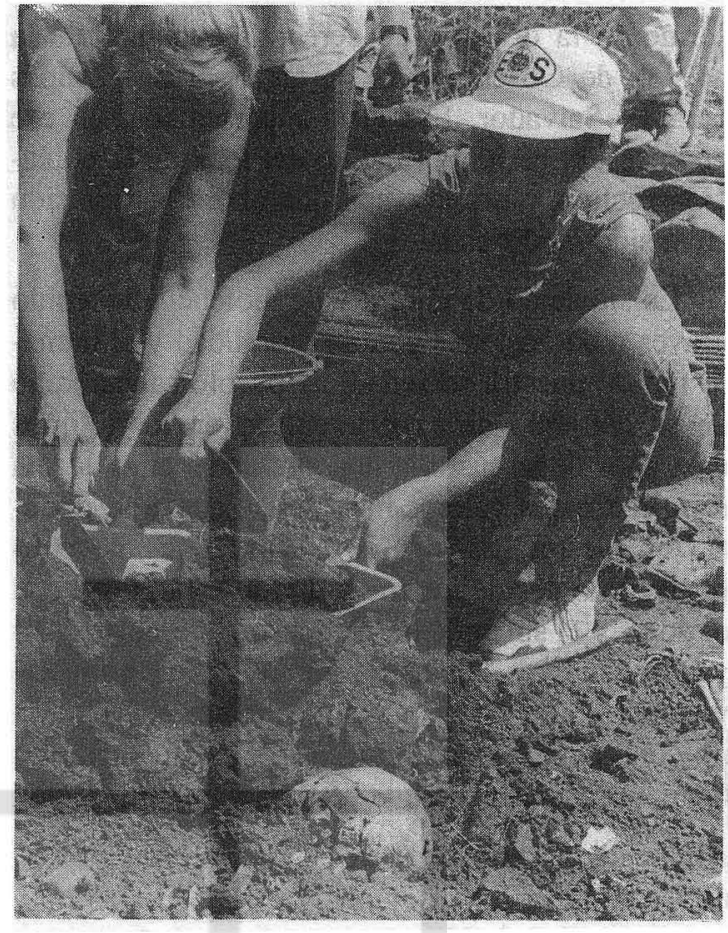

existia en el país un "gobiemo de facto", obviando que en esos momentos era la misma Fuerza Armada la que estaba en el poder, junto con la democracia cristiana. En ningún momento, la continuidad del mando y el control de la administración, la logística, la información, las operaciones y el personal se ha perdido en la Fuerza Armada. A ello, se debe agregar la inexplicable defensa incondicional del batallón Atlacatl, responsable de la masacre de El Mozote, hecha por el presidente Cristiani.

El temor fundado ante la inseguridad cotidiana es válido. La gravedad del fenómeno exige soluciones justas y adecuadas, en concordancia con el respeto de los derechos humanos. En El Salvador existe ahora una inigualable oportunidad para salir del ostracismo social y jurídico en el que hemos vivido sumergidos. Esta situación exige superar anacronismos legales que sólo han beneficiado a un poderoso sector y condenado al resto de la población a sufrir el peso de un aparato encargado de "administrar injusticias". Prueba de ello son las 4,755 personas que, sin condena, se encontraban en los centros de reclusión en el país hasta el 6 de marzo de 1992, tal como lo registró el cuarto in- 
forme de la división de derechos humanos de la Misión de Observadores de las Naciones Unidas para El Salvador. Esa cifra representaba, en ese entonces, el 89.95 por ciento del total de la población reclusa y no creemos que ahora la situación haya sido modificada.

La situación de guerra y de violencia ha tenido graves repercusiones para la moralidad y el humanismo de nuestra sociedad. El pueblo salvadoreño en su conjunto ha experimentado en los últimos diez años de su historia una alteración en la forma de apreciar los valores humanos. Lamentablemente, en nuestra sociedad se han perdido los sentimientos nobles de fraternidad y de solidaridad con el dolor y el sufrimiento de nuestros hermanos salvadoreños. Nos hemos acostumbrado a la muerte violenta como un acontecimiento normal, que ya no conmueve ni altera nuestros sentimientos. Nos hemos acostumbrado a la pérdida y a la restricción ilegitima de la libertad sin que ello nos haga reflexionar en su importancia para la esencia misma del ser humano. Nos hemos acostumbrado a aceptar el culto a la violencia como algo cotidiano en nuestro país, olvidándonos que una sociedad humana y justa se construye mediante la promoción de la cultura de la democracia y del respeto de los derechos humanos. No es tiempo de posturas extremistas, contrarias a la dignidad humana. Una buena legislación -más que suiza o estadounidense - salvadoreña, acompañada por una correcta aplicación de la misma por funcionarios capaces y honestos, es un interesante reto para que el Estado empiece a cumplir con su papel de garantizar la seguridad ciudadana y hacia ese objetivo deberían estar dirigidos todos nuestros esfuerzos. Para ello, debemos también contribuir con un debate serio que eduque a la población y le renueve su capacidad de indignación frente a todos estos hechos.

IDHUCA 